\title{
Vegetation Drought Dynamic Analysis in European Russia
}

\author{
M S Boori ${ }^{1,2,3}$, R Paringer ${ }^{1,4}$, K Choudhary ${ }^{1,2,5}$ and A Kupriyanov ${ }^{1,4}$ \\ ${ }^{1}$ Samara National Research University, Moskovskoe Shosse 34A, Samara, Russia, 443086 \\ ${ }^{2}$ University of Rennes 2, Rennes, France \\ ${ }^{3}$ American Sentinel University, Colorado, USA \\ ${ }^{4}$ Image Processing Systems Institute of RAS - Branch of the FSRC "Crystallography and \\ Photonics" RAS, Molodogvardejskaya street 151, Samara, Russia, 443001 \\ ${ }^{5}$ The Hong Kong Polytechnic University, Hong Kong \\ e-mail: msboori@gmail.com
}

\begin{abstract}
This research work deals with the spatial-temporal characteristics of the relationship between drought events (Standardized Precipitation Index [SPI]), land surface temperature (LSI) and vegetation indexes (VIs) in the spring-summer (May-August) over the European Russia (ER) from 2000 to 2018. We use Terra- MODIS - NDVI and LST product and TRMM for rainfall data. Statistical results indicate that year 2004, 2009 and 2015 were the most significant changing-point in mean annual rainfall values and VIs. Results indicate that vegetation area and VIs variate according to SPI values. Analysis results also indicate that low NDVI values (0.2-0.4) shift in high NDVI values (0.5-0.8) with high SPI values and viceversa, also high LST values associated with low VIs values and vice-versa, with correlation coefficients 0.90 , means high-temperature show low vegetation. Correlation analysis of VIs, SPI and LST deficit shows that vegetation is closely related to rainfall and temperature, especially under the dry and wet conditions and indicates that this correlation can use for nearreal-time monitoring of vegetation drought dynamics. All predictions and monitoring using satellite-derived VIs is a low cost and effective means of identifying longer-term changes as opposed to natural inter-annual variability in vegetation growth.
\end{abstract}

\section{Introduction}

This is a global phenomenon that rainfall and temperature are the key parameters for vegetation condition, health, growth and responsible for a wide range of forest ecosystem. Globally, maximum forest areas are under mortality situation due to increasing temperature and reducing soil moisture [1, 2]. Simultaneously, we have a lot of evidence, that under future climate scenario, maximum world forest area will suffer increasing forest mortality rate due to severe and frequent drought events [3], especially in dry parts of the world [4]. Among the various factors, climate change is influencing serious negative trends in forest ecosystem structure and function by expected increase drought intensity and frequency [5]. Coping with these consequences of climate change represents in many forest regions, such as changes in rainfall patterns, increase average temperature, increase in drought frequency, intensity and can impede tree vulnerability [6], increase mortality rate [7] and seem to have a significant impact on the growth and development of forest in all over the world [8, 9, 10]. As vegetation condition, rainfall and temperature have a close relationship so any change in rainfall pattern and temperature will have a significant impact on the growth and potentially triggering large- 
scale changes in the forest distribution, structure, function, and composition [11] and threatening terrestrial net primary production [12]. Still, the relationship between vegetation, rainfall, and the temperature is of fundamental importance [13]. Specifically, reducing rainfall and increasing temperature are reducing soil moisture and the increasing possibility of severe drought events, which increase evaporation rate and salinity, that directly effect on net production, growth and survival, ultimately loss of biodiversity, ecosystem and increase forest vulnerability to other human natural stress $[14,15,16]$. So to predict future forest ecosystem with climate change is a basic requirement to understand the ecological mechanisms with governing vegetation droughts dynamics [17]. The Russian climate is influenced by severing factors [18] such as southern mountains, a plain area in the west, Indian Ocean warm-air and the Arctic and Atlantic influences in the north. Russia has extreme dry winter or precipitation as a high snowfall in winter and hot summer with rains [19] with a semiarid climate. Around 65\% Russian territory comes under permafrost with 65-75 cm (24-30in) Annual precipitation but in the south part, its only $4-5 \mathrm{~cm}(1-2$ in) annual precipitation [18] so extreme weather condition have been badly effecting on vegetation in ER [20].

Human society and the global economy are closely linked with forest in terms of their livelihood, providing food, water, wood products, medicines and in last supporting biodiversity [21]. ER forest spread for $2000 \mathrm{~km}$ from $66^{\circ} \mathrm{N}$ to $53^{\circ} \mathrm{N}$ with $1 / 4$ of the world's reserves wood [22]. The Russian timber industry is one of the oldest industries which provide around 20 billion dollars per year in the Russian economy. The main species of coniferous tree are pine, spruce, larch, cedar. Despite this Russian forest ecosystem is endangered by harvest, fuel, grazing, farming, industrial development, construction, mining, pollutions, forest fire, unmanaged tourism, and non-native wildlife animals destroy seeds, trunks, and branches and put further stress on the ecosystem [23]. Tree vulnerability to drought estimation based on the surveys, visual interpretation of canopy conditions and expert knowledge is expensive, time-consuming, less accurate, require more manpower, difficult to extrapolate over large, inaccessible areas and tough in regular monitoring [20]. Satellite remote sensing, on the other hand, has several advantages due to its repetitive, synoptic coverage of large, inaccessible areas in a quick and economical fashion [24]. Remotely sensed data has been used to monitor the impacts of drought on canopy water loss, ecosystem carbon dynamics and water use efficiency [25]. Other hand many regions especially inaccessible area, where the density of meteorological stations are not sufficient or frequency of data collection are low and field work is impossible than drought monitoring is not possible accurately based on rainfall data. But satellitebased rainfall data is continuously available for the large, inaccessible area and quickly on low cost or free of cost with the availability of historical data. That's why remote sensing is proved a powerful tool for measuring and monitoring of drought conditions with temporal and spatial aspects [26]. There is a lot of ways to monitor and mapping forest disturbance by insect and burning using satellite remote sensing [27]. Same-date high resolution multispectral and hyperspectral imagery such as IKONOS and Hyperion and multi-date imagery from medium resolution can easily detect insect outbreaks [28]. The Ecosystem Disturbance and Recovery Tracker (eDaRT) system, for example, is being developed by many countries for forest disturbance mapping and monitoring with medium resolution satellite data [29]. These methods can detect high- and moderate-magnitude disturbances at a relatively high spatial resolution, such as fire burns, clear-cuts or severe mortality [30]. But still, regular monitoring of tree vulnerability on a large area is a chilling task [31].

The main cause of drought is the shortage of rainfall in terms of low water availability from the average annual condition and it's related to increasing temperature and evaporation, which effect on local vegetation condition. In ER long term drought occurrence and significant changes in rainfall patterns are the most imperative factor, which affects the vegetation. The effects of drought occurrence on vegetation in the ER have not been computed yet. Currently, various drought indicators have been used for drought events effect on vegetation including meteorological [32], remotely sensed, hydrological and other indicators to measure drought impacts. Other than this traditional method of drought assessment and monitoring based on rainfall data are palmer drought severity index (PDSI) [33], SPI [34] and Palmer hydrological drought index (PHDI) [35]. The easy-to-use SPI has been widely employed to determine the occurrence of drought episodes and enables investigations of water deficiencies at different spatial and temporal scales $[36,37,38]$. The main objective of this research 
work is to identify a relationship between spatial-temporal change in drought events [rainfall (SPI)] and temperature (LST) for vegetation condition. This research work enumerates the relationship in between vegetation with droughts intensities and trends to protection and restoration of ER vegetation on timely and effectively. For that, we used satellite and long term rainfall data from 2000 to 2018 for ER and figured out SPI to identify changes in rainfall patterns, which show changing-point year, that indicate drought dynamics in last two decades. Then we correlate SPI and drought occurrence to identify changes in the vegetation area and condition in the ER. We also quantify the changes in vegetation condition and area separately for the intervals before and after of the changing-point years.

\section{Study area}

The study area of this research work is the entire European Russia (figure 1). Russia is the world's largest and a transcontinental country. European Russia is the western part of Russia that is a part of Eastern Europe, with a population of 110 million people, European Russia has about $77 \%$ of Russia's population, but covers $23 \%$ of Russia's territory; and occupies almost $40 \%$ of Europe's total area.

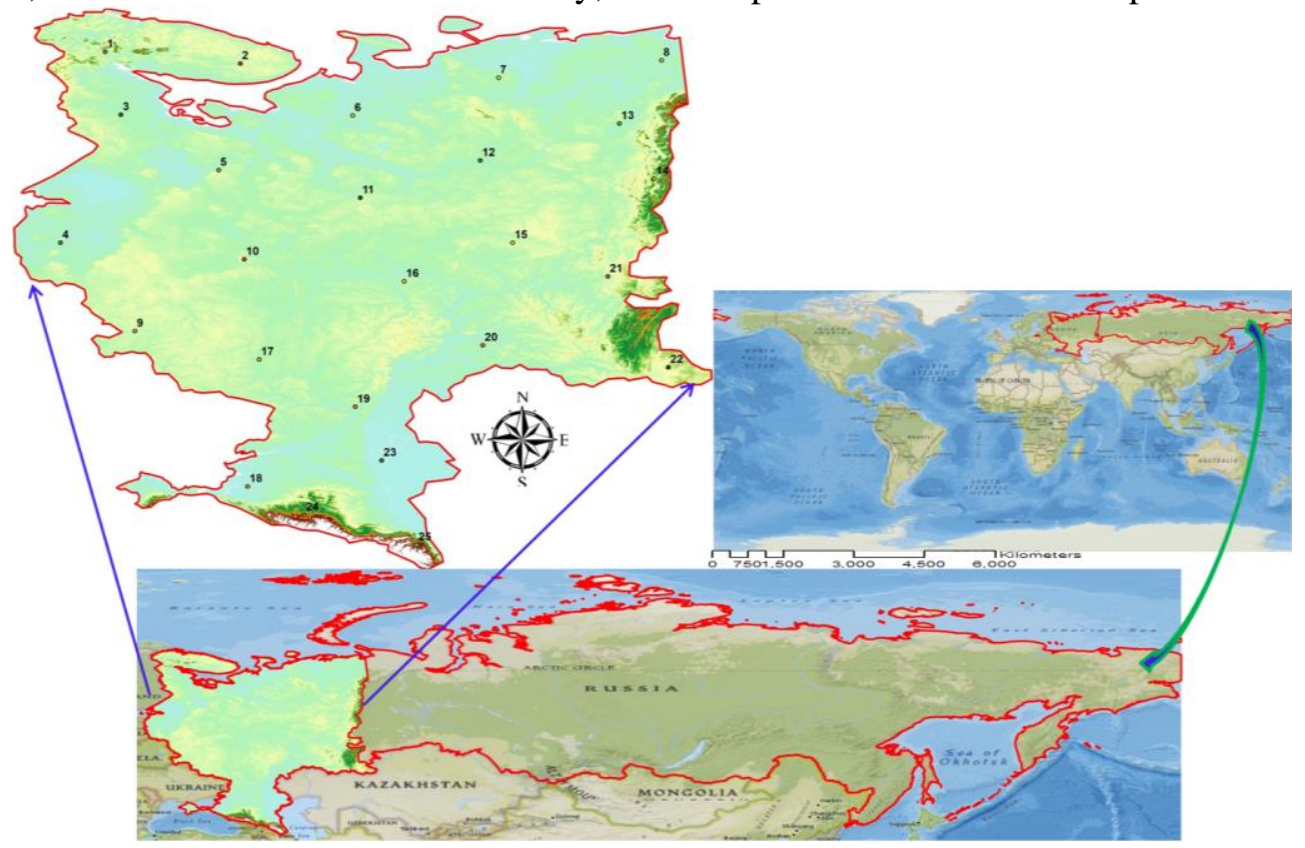

Figure 1. The geographic location of European Russia with 25 rainfall sampling location and DEM.

\section{Materials and methods}

\subsection{Datasets}

To obtain a sufficient spatial and temporal coverage of the study area on a yearly basis and at low costs, multispectral data were download from united states geological survey (USGS) website such as advance very high-resolution radiometer (ASTER), MODIS and global land data assimilation system (GLDAS) Noah land surface model [39]. We used MODIS product MOD11A2 for LST, MOD13Q1 for VIs and MOD09Q1 for surface reflectance information. For elevation and slope information we used ASTER-GDEM with $30 \mathrm{~m}$ spatial resolution and for rainfall measurements or SPI, national aeronautics and space administration (NASA) global land data assimilation system (GLDAS) and other meteorological data were used. During fieldwork, we used high-quality handheld global positioning system (GPS) for ground truth and to georeference satellite images. In secondary data, we used other ancillary data and ground data from meteorology, climatology, agriculture, forest and survey departments such as geology and geography (topographic sheets). For geographical information system (GIS) analysis and image processing work, we used ArcGIS, ER-Mapper and ERDAS software's and prepare thematic maps with the help of satellite data, topographic maps, field, and ancillary data: such as vegetation, digital elevation model (DEM), rainfall, NDVI, LST. So to take 
the dual advantage in this research work, we used both primary (satellite data) and secondary data (field and socio-economic data). Mainly we use MODIS instrument, which is operating on both the Terra and Aqua spacecraft. It has a viewing swath width of 2,330 km and views the entire surface of the Earth every one to two days. Its detectors measure 36 spectral bands between 0.405 and $14.385 \mu \mathrm{m}$ and it acquires data at three spatial resolutions -- $250 \mathrm{~m}, 500 \mathrm{~m}$ and $1,000 \mathrm{~m}$. MODIS products are available from several sources such as LAADS web, DAAC at the U. S. geological survey.

\subsection{Pre-processing}

This research work was benefited from ground-based information collected during fieldwork. Then complete image pre-processing steps such as remove all radiometric, geometric distortions and projected all datasets in world geodetic system - 1984 universal transverse Mercator coordinate system (WGS-1984 UTM) projection with the help of ground control points (GCP) so that all noise or sensors related errors such as droplines was removed and each pixel was geocoded as its exact location on the globe and then used best band combination and enhancement techniques to identify specific features in false color composite images. After it, all field data were vectorized and interpolated as grid datasets so that it was combined with satellite data and later on easy to use in GIS format analysis, which was a great help to derive meteorological information, phonological information and vegetation based indices for vegetation drought dynamics.

\subsection{NDVI \& LST}

Following the streamlines in methodology, after image processing, all satellite data was processed for the mapping of vegetation indices - VIs (NDVI \& EVI) and LST. For vegetation indices (NDVI \& EVI) a 16-day time series L3 global 250m resolution MODIS product MOD13Q1 and an 8 day L3 Global $1 \mathrm{~km}$ average value of the composite LST MODIS product MOD11A2 were used in the study area from 2000 to 2018. NDVI is a proxy for photosynthetic activity and primary production from vegetation biomass and is a common index for monitoring vegetation health. Enhanced vegetation index (EVI) is similar to NDVI but less sensitive to noise from background soil and atmospheric conditions and less saturated in high-biomass areas. Here VIs was calculated from visible and infrared bands combinations in ArcGIS software, whereas LST was calculated by thermal bands (ground emissivity) combinations. VIs was helping to identify forest canopy cover mapping and vegetation condition index (VCI), while LST can measure temperature condition index (TCI). The important thing is that NDVI generated VCI and LST generated TCI was useful to make vegetation health index (VHI), which show the actual vegetation health condition.

These continuous VIs and LST time series values were helpful to calculate the baseline and change metrics of forest health for tree vulnerability detection to drought. MODIS MOD11A2 product consists of 16-bit unsigned integer values from 7500 to 65500 and to derive actually ground temperature in Kelvin, need to multiply it with scaling factor 0.02 [40]. In NDVI some values are zero or less than zero, which represent water body or the cloud in the image so need filters and finally generate maps of the study area from 2000 to 2018.

\subsection{NASA Global Land Data Assimilation System (GLDAS Noah Surface Model)}

This data product is a replacement for GLDAS-1 0.25 -degree monthly data product. Global land data assimilation system version 2 (hereafter, GLDAS-2) has two components: one forced entirely with the Princeton meteorological forcing data (hereafter, GLDAS-2.0), and the other forces with a combination of model and observation based forcing data sets (hereafter, GLDAS-2.1). This research work used this data for calculating the meteorological drought index (SPI). GLDAS Noah land surface model combines remotely sensed precipitation estimation with land surface gauge analysis and was help precipitation rates and vegetation response to rainfall over the accumulation period for each pixel as the amount of rainfall associated with vegetation condition.

\subsection{Standardized precipitation index (SPI)}

Generally, rainfall directly effects on temperature and soil moisture and later on vegetation. Normally in high rainfall regions, vegetation is very healthy and dense. A short time period of SPI values (1 to 3 
months) is related to soil moisture changes that have a greater effect on agriculture. A longer time period (6 to 12 months) SPI values show longer time period change on precipitation, available water, land use/cover and ecosystem. This research work used almost two-decade summer rainfall data (May to Aug months.) from 2000 to 2018 to access the change in drought and to determine changing-point in rainfall pattern in ER (fig. 2). Figure 1 shows the location of all 25 rainfall stations from where we collect rainfall data and derive a relationship between drought and vegetation indices.

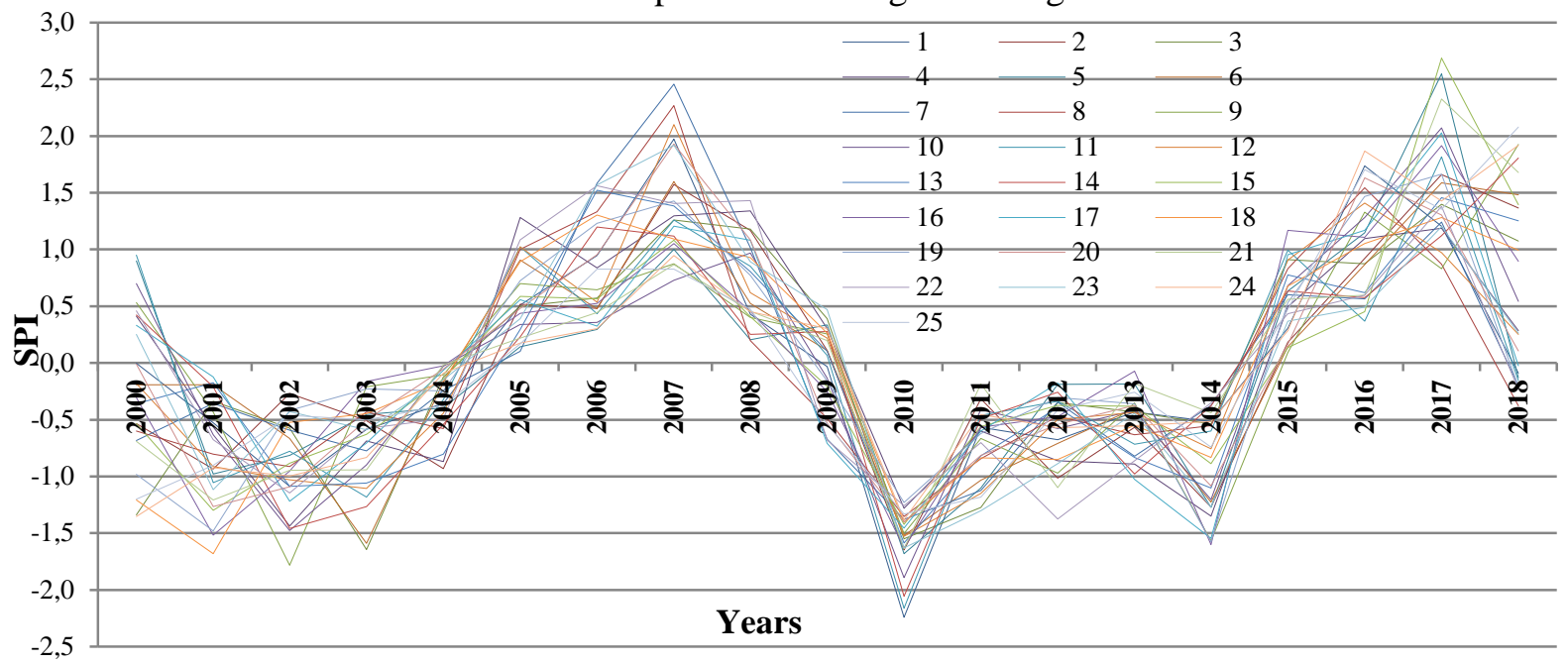

Figure 2. SPI based drought identification from 25 rainfall stations in ER from 2000 to 2018. SPI values above 2 indicate extreme wetness, between 2 and 1 severe to moderate wetness, between 1 and -1 normal condition, between -1 and -2 moderate to severe droughts and below -2 extreme droughts.

\subsection{Change point detection}

To detect changes in vegetation with drought, change point or breakpoint identification in rainfall pattern is a compulsory thing which helps to understand the whole ecosystem process. A changing point is defining a point where frequency and distribution of variables change their direction for a time (figure. 2). There are many methods to identify change point such as $[42,43,44,45]$ tests that enable detection of changes in a data series. This research work defines change point in a time series of rainfall by using Pettitt-Mann-Whitney-Test and cumulative sum method (CUSUM) in the Change Point Analyzer (CPA) software [42]. The CUSUM method is a very simple and flexible method and originally developed for controlling industrial process and can use in trained data in place of natural data. Many times it used in environmental monitoring programs to identify change point in time series of environmental and climatic variables. After identifying change point in rainfall data series, we confirm it with t-test by comparing the mean value of rainfall data before and after the change years.

\subsection{Mapping VIs area}

Vegetation health or condition and total vegetation cover area are highly correlated with NDVI values [46]. To identify changes in vegetation health over a period of time, we used [47] method that change in NDVI values are proxy of change in vegetation condition. According to this, we classify NDVI values in terms of very healthy to no vegetation class as in table 1. Finally, first we calculate total vegetation and non-vegetation area and then subclass level vegetation area according to NDVI values as table 1 for over the last two decades from 2000 to 2018 for European Russia. As atmospheric condition were different for the different years during the image capturing so field work was an important task to increase accuracy in subclass level vegetation area calculations. For accuracy assessment of the all yearly NDVI maps from 2000 to 2018, 250 sampling plots with $30 * 30 \mathrm{~m}$ were established in the entire study area. Other than this we also take help from Arial photos, highresolution satellite data, and ancillary data related to vegetation for accuracy assessment and derive user accuracy, producer accuracy, and overall accuracy. Finally, calculate total area change in vegetation as well as area change in different NDVI values for the period before and after the 
change/breakpoint year in the time series of rainfall data. Here we also did a key interview with old peoples who live in the study area for a long time (more than 25 years).

Table 1. Vegetation classes according to NDVI values.

\begin{tabular}{|c|c|c|c|c|c|c|}
\hline $\begin{array}{l}\text { Class } \\
\text { name }\end{array}$ & $\begin{array}{l}\text { NDVI } \\
\text { range }\end{array}$ & Class level I & $\begin{array}{l}\text { Class level } \\
\text { II }\end{array}$ & Class level III & NDVI range & $\begin{array}{c}\text { Subclass } \\
\text { name }\end{array}$ \\
\hline 1 & 0.9 to 1 & & $\begin{array}{c}\text { Dense } \\
\text { vegetation }\end{array}$ & $\begin{array}{l}\text { Very healthy } \\
\text { vegetation }\end{array}$ & $0.85<$ & A \\
\hline 2 & 0.5 to 0.8 & Vegetation & $\begin{array}{c}\text { Open } \\
\text { vegetation }\end{array}$ & $\begin{array}{l}\text { Temperate and } \\
\text { tropical rainforests }\end{array}$ & $\begin{array}{l}0.79-0.84 \\
0.66-0.78 \\
0.51-0.65\end{array}$ & $\begin{array}{l}\text { B } \\
\text { C } \\
\text { D }\end{array}$ \\
\hline 3 & 0.2 to 0.4 & & $\begin{array}{l}\text { Degraded } \\
\text { vegetation }\end{array}$ & Shrub and grassland & $\begin{array}{l}0.41-0.50 \\
0.31-0.40 \\
0.20-0.30\end{array}$ & $\begin{array}{l}\mathrm{E} \\
\mathrm{F} \\
\mathrm{G}\end{array}$ \\
\hline 4 & -0.1 to 0.1 & No- & & $\begin{array}{c}\text { Barren areas of rock, } \\
\text { sand, or snow }\end{array}$ & $0.00-0.19$ & $\mathrm{H}$ \\
\hline 5 & -0.1 to -1 & Vegetation & & Water & $\begin{array}{c}0.00--0.50 \\
\quad-0.51>\end{array}$ & $\begin{array}{l}\mathrm{I} \\
\mathrm{J}\end{array}$ \\
\hline
\end{tabular}

\section{Results}

\subsection{SPI patterns}

Figure 2 shows the spatial and temporal pattern of SPI from 2000 to 2018 in the summer month from 25 rainfall stations in the ER. As above or positive values of normal rainfall distribution show wetness and negative or below values of normal rainfall indicate dryness. SPI values above 2 indicate extreme wetness, between 2 and 1 severe to moderate wetness, between 1 and -1 normal condition, between -1 and -1 moderate to severe droughts, and below -2 extreme droughts.

We find that from 2001 to 2004 all SPI values falls 0 to -1.5 , which show moderate to the severe dry situation and from the year of 2004 all values move to the positive direction so the year 2004 was a changing point year. From 2005 to 2009 all SPI values were in a positive direction, means its show wet weather condition. The Year of 2007 has 2.5 SPI values means it was the extreme wet condition year. The year 2009 was again a changing point year as all values go in a negative direction till 2014, with the extremely dry year of 2010. From 2015 SPI values again move in the above direction with the extreme wet year 2017. In short, we find 3 changing point years as 2004, 2009 and 2015. We also find that year 2007 and 2017 have the extreme wet condition and year 2010 had an extremely dry condition (figure 2) so based on SPI values from 2000 to 2018, the wet and dry years patterns can be divided into four parts.

Maximum parts of the study area were the tendency of decreasing SPI values special from 2001 to 2004 and then 2009 to 2014, which show the increasing dryness in the different parts of the study area. The southern and southeast part of the ER was maximum affected area due to dryness and severe droughts.

\subsection{Rainfall analysis}

With the help of Pettit-Mann-Whitney method, we find the maximum probability of change year was 2004, 2009 and 2015 from the period of 2000 to 2018 from all 25 rainfall stations (figure 3). In particular these years, there was a significant change in mean summer rainfall. This was also confirmed by the CUSUM method. Figure 3 represent maximum, minimum, mean and standard deviation values of rainfall for spring-summer (May-August) season from 2000 to 2018 in European Russia. Figure 3 also shows that the year 2007 and 2017 have the highest rainfall and year 2010 had the lowest rainfall in the study area. 


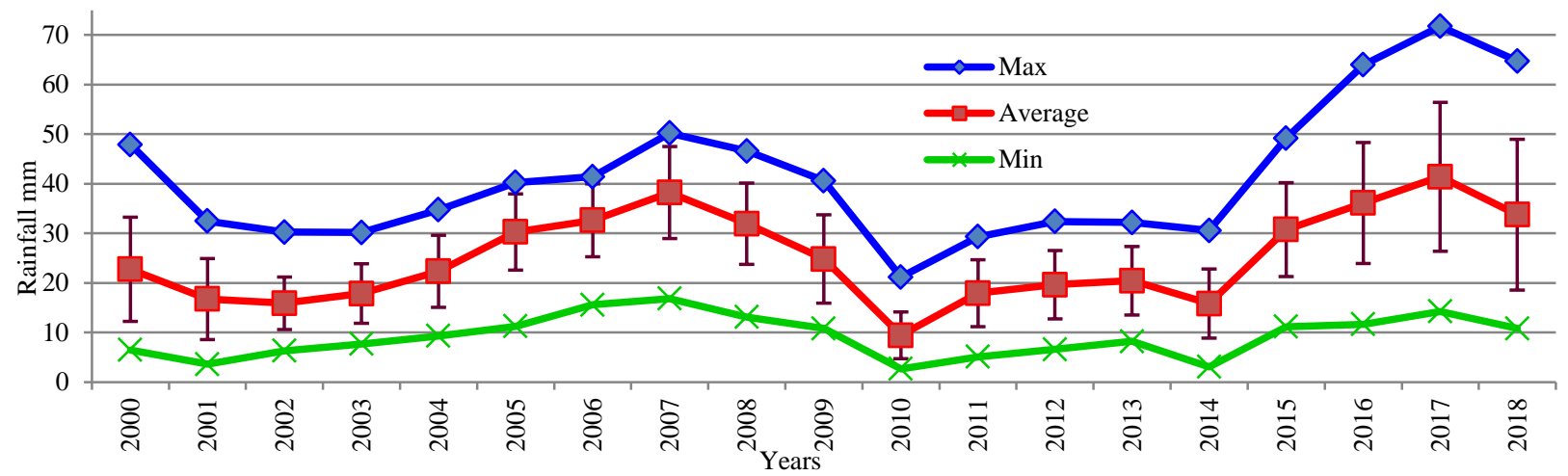

Figure 3. Maximum, minimum, average and standard deviation values of rainfall (mm) for springsummer (May-August) season from 2000 to 2018.

\subsection{Analyses of vegetation cover change}

The satellite image analysis of vegetation cover in European Russia from 2000 to 2018 showed a significant change in the area between vegetation and non-vegetation (figure 4). Total vegetation area (A to G NDVI classes) was continuously increased from 2001 to 2007 and reach $3582036 \mathrm{~km}^{2}$ in 2007 and it was highest as $3681070 \mathrm{~km}^{2}$ in 2017 . The non-vegetation area was highest as 982348 and $895479 \mathrm{~km}^{2}$ in 2000 and 2010 respectively (figure 4).

\subsection{Analysis of SPI and VIs relationship}

Analysis results show that VIs area was increased with increased SPI values and decreased with decreasing SPI values (reducing rainfall or more drought condition). The correlation and coefficients of SPI and VIs have linear regression $\left(\mathrm{R}^{2}\right)$ exceeded 0.90. According to SPI values, as the year 2010 was the driest year from 2000 to 2018 period and it's also represented by non-vegetation area as it was highest in 2010 (figure 4). When compare the highest values of SPI as it was in the year 2007 and 2017, we find that total vegetation cover area was also highest in both years (figure 4). So this research work confirms that SPI values are also associated with vegetation indices (VIs). As high SPI values represent high VIs values and vice-versa.

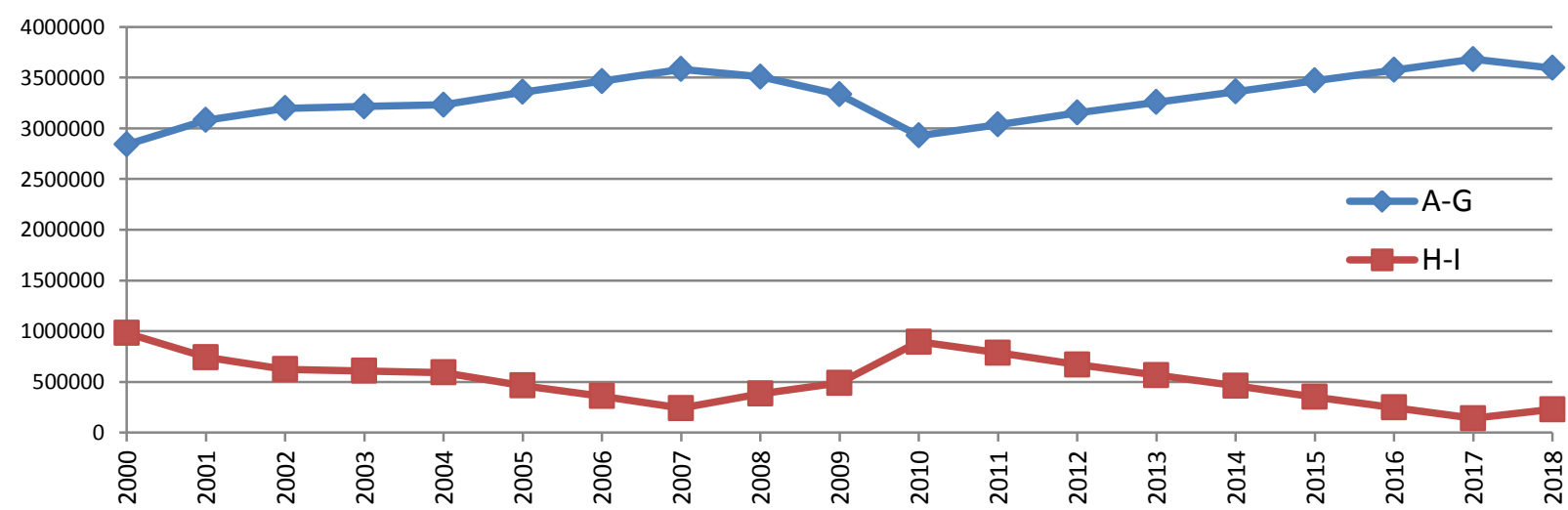

Figure 4. Vegetation and non-vegetation area in ER from 2000 to 2018.

\subsection{LST and VIS}

To get a relationship between LST and VIs, we used Pearson correlation coefficient during two decades study period (figure 5) and find a clear negative correlation. The correlation coefficient of determination of each linear regression $\left(r^{2}\right)$ exceeded more than 0.90 in all years [48, 49]. Extreme temperature shows low vegetation and reducing temperature represent increasing high and healthy vegetation condition. Here EVI has high correlation than NDIV as it's not affected by background features effects (figure 5). 

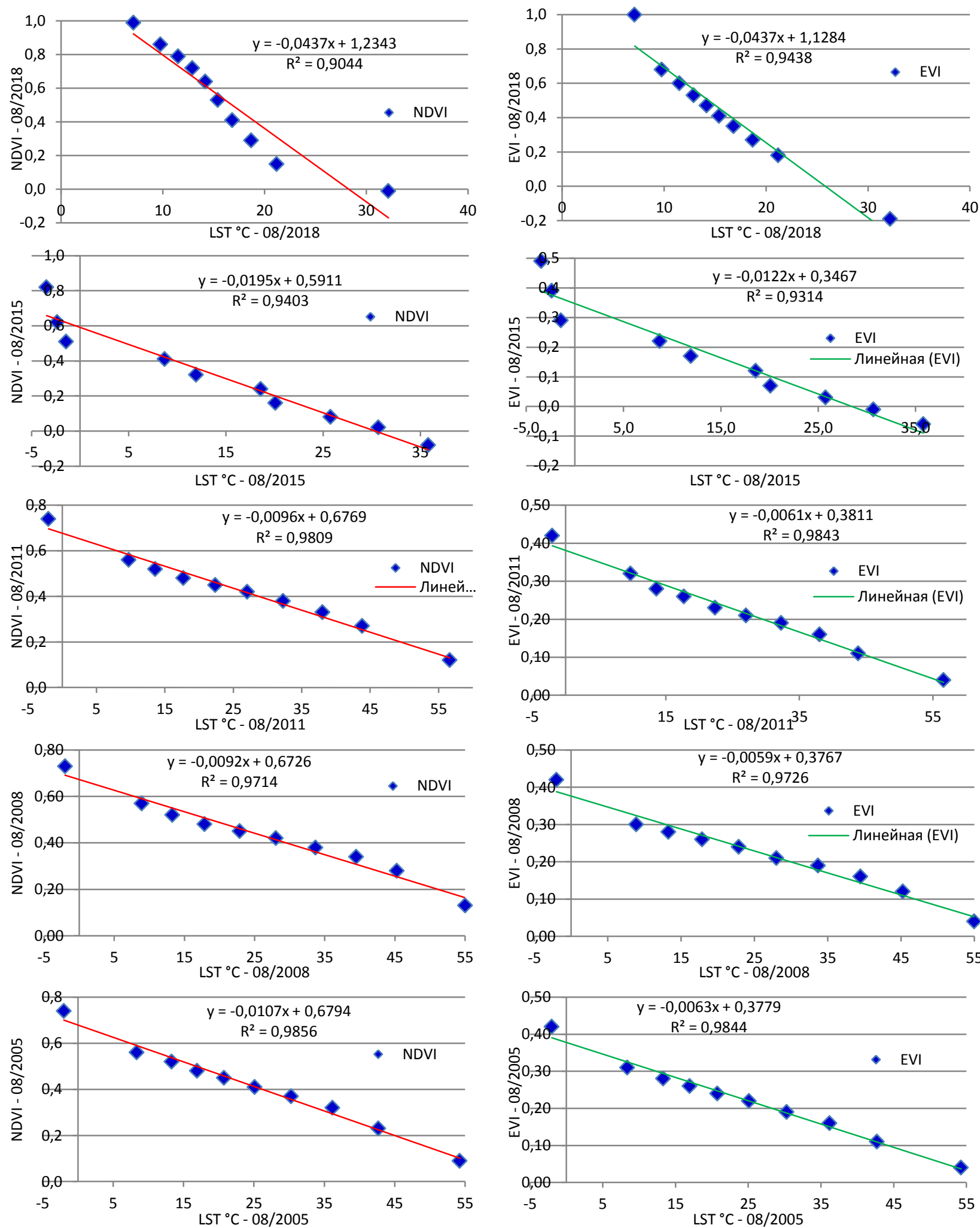

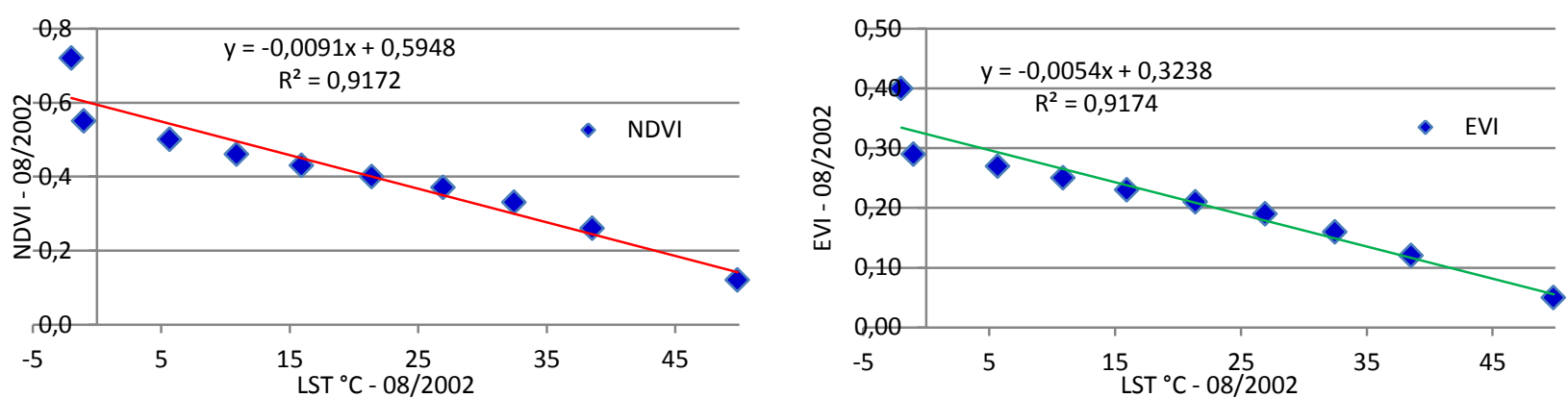

Figure 5. LST and VIs relationship during spring-summer (May-August) season from 2000 to 2018.

Normally VIs represents the land use feature and LST symbolizes thermal condition of land surface features [50]. Figure 4 illustrates the relationships between VIs (NDVI \& EVI) for the different years' time period in European Russia from 2000 to 2018. In general, the NDVI value increases with enhanced vegetation coverage. It is easy to understand that higher vegetation coverage would lead to lower LST; however, when the NDVI is below a certain value, the LST appears to increase with the VIs [51].

\section{Conclusion}

This research work analysis three primary data (Rainfall, LST and VIs) and identify a relationship between climate condition and its direct effect on vegetation. A reduction in rainfall and high LST are increasing drought occurrence, which also indirectly influenced by human interference. The main work was using SPI time series values from rainfall and detects changes in drought and later on its effect on vegetation covers area and vegetation condition with LST. Especially identification of changing point $(2004,2009,2015)$ and extreme wet $(2007,2017)$ and extreme dry years $(2002,2010)$ and effects on vegetation with LST relationship in between different time periods. The southern part of the study area was maximum affected by severe drought with high LST and low VIs. Understanding these relationships and the characteristics of droughts is crucial for improving our knowledge of vegetation vulnerability to climate fluctuations and climate change for vegetation drought dynamics.

\section{References}

[1] Anderegg W R L 2012 The roles of hydraulic and carbon stress in a widespread climate-induced forest die-off Proc Natl Acad Sci USA 109(1) 233-237

[2] Adams H D, Zeppel M J B, Anderegg W R L, Hartmann H, Landhäusser S M, Tissue D T, Huxman T E, Hudson P J, Franz T E and Allen C D 2017 A multispecies synthesis of physiological mechanisms in drought induced tree mortality Nature Ecology and Evolution 1 1285-1291

[3] Dai A 2013 Increasing drought under global warming in observations and models Nature Climate Change 3 52-58 DOI: 10.1038/nclimate1633

[4] Steinkamp J and Hickler T 2015 Is drought-induced forest dieback globally increasing? Journal of Ecology 103 31-43

[5] Rigling A, Bigler C and Eilmann B 2013 Driving factors of a vegetation shift from Scots pine to pubescent oak in dry Alpine forests Global Change Biology 19 229-240

[6] van Mantgem P J, Stephenson N L and Byrne J C 2009 Widespread increase of tree mortality rates in the Western United States Science $\mathbf{3 2 3}$ 521-524

[7] Urrego L E, Correa-Metrio A, Gonzalez C, Castano A R and Yokoyama Y 2013 Contrasting responses of two Caribbean mangroves to sea-level rise in the Guajira Peninsula (Colombian Caribbean) Palaeogeogr. Palaeoclimatol. Palaeoecol 370 92-102

[8] Alongi D M 2015 The impact of climate change on mangrove forests Curr. Clim. Change Rep. 1(1) $30-39$ 
[9] Galeano A, Urrego L E, Botero V and Bernal G 2017 Mangrove resilience to climate extreme events in a Colombian Caribbean Island Wetl. Ecol. Manag 25(6) 743-760 DOI: 10.1007/s11273-017-9548-9

[10] McIntyre P J, Thorne J H, Dolanc C R, Flint A L, Flint L E, Kelly M and Ackerly D D 2015 Twentieth-century shifts in forest structure in California: denser forests, smaller trees, and increased dominance of oaks Proceedings of the National Academy of Sciences of the USA 112 $1458-1463$

[11] Zhou X, Yamaguchi Y and Arjasakusuma S 2018 Distinguishing the vegetation dynamics induced by anthropogenic factors using vegetation optical depth and AVHRR NDVI: A crossborder study on the Mongolian Plateau Science of The Total Environment 616-617 730-743

[12] Asbridge E, Lucas R, Ticehurst C and Bunting P 2016 Mangrove response to environmental change in Australia's Gulf of Carpentaria Ecol. Evol. 6(11) 3523-3539

[13] Djebou D C S, Singh V P and Frauenfeld O W 2015 Vegetation response to precipitation across the aridity gradient of the southwestern United States J. Arid Environ $11535-43$

[14] Brandt M, Tappan G, Diouf A A, Beye G, Mbow C and Fensholt R 2017 Woody vegetation die off and regeneration in response to rainfall variability in the west African Sahel Remote Sens 9(1) p 39

[15] Williams A P, Allen C D and Macalady A K 2013 Temperature as a potent driver of regional forest drought stress and tree mortality Nature Climate Change 3 292-297

[16] Bruno A 2018 Climate history of Russia and the Soviet Union WIREs Climate Change 9(5) e534

[17] Marengo J A, Alves L M, Alvala R C S, Cunha A P, Brito S and Moraes O L L 2018 Climatic characteristics of the 2010-2016 drought in the semiarid Northeast Brazil region Anais da Academia Brasileira de Ciências 90(2) 1973-1985

[18] Goodarzi M, Pourhashemi M and Azizi Z 2019 Investigation of Zagros forests cover changes under recent droughts using satellite imagery J. For. Sci 65 9-17

[19] Asner G P, Brodrick P G, Anderson C B, Vaughn N, Knapp D E and Martin R E 2016 Progressive forest canopy water loss during the 2012-2015 California drought Proc. Natl. Acad. Sci. The USA 113 E249-E255

[20] Klein T, Cahanovitc R, Sprintsin M, Herr N and Schiller G 2019 A nation-wide analysis of tree mortality under climate change: Forest loss and its causes in Israel 1948-2017 Forest Ecology and Management 432 840-849

[21] USDA 2016 New Aerial Survey Identifies More Than 100 Million Dead Trees in California (USDA: Vallejo, CA, USA)

[22] Liang L 2015 Remote Sensing Monitoring and Ecological Modeling of Insect Outbreak Dynamics in the Southern Rocky Mountains Ecoregion Ph.D. thesis: University of California, Berkeley

[23] Slaton M, Koltunov A and Ramirez C 2016 Application of the Ecosystem Disturbance and Recovery Tracker in Detection of Forest Health Departure from Desired Conditions in Sierra Nevada National Forests

[24] Wulder M A, White J C, Coops N C and Buston C R 2008 Multi-temporal analysis of high spatial resolution imagery for disturbance monitoring Remote Sens. Environ 112 2729-2740

[25] Cohen W B, Yang Z, Stehman S V, Schroeder T A, Bell D M, Masek J G, Huang C and Meigs GW 2016 Forest disturbance across the conterminous United States from 1985-2012: The emerging dominance of forest decline For. Ecol. Manag 360 242-252

[26] Wilhite D A, Svoboda M D and Hayes M J 2007 Understanding the complex impacts of drought: a key to enhancing drought mitigation and preparedness Water Resour. Manage 21 763-774

[27] Labe dzki L 2017 Categorical forecast of precipitation Anomaly using the standardized precipitation index SPI Water $\mathbf{9 ( 1 )}$ p 8

[28] Kamali B, Houshmand Kouchi D, Yang H and Abbaspour K C 2017 Multilevel drought hazard assessment under climate change scenarios in semi-arid regions- a case study of the Karkheh river basin in Iran Water 9(4) p 241 
[29] Wan Z, Hook S and Hulley G 2015 MOD11A2 MODIS/Terra Land Surface Temperature / Emissivity 8-Day L3 Global 1km SIN Grid V006 [Data set] NASA EOSDIS LP DAAC

[30] Lee A F and Heghinian S M 1977 A shift of the mean level in a sequence of independent normal random variables-a bayesian approach Technometrics 19(4) 503-506

[31] Hubert P, Carbonnel J P and Chaouche A 1989 Segmentation des series hydro-meteorological application des series de precipitations et de debits de l'Afrique de l'ouest J. Hydrol 110(3) 349367

[32] Berdanier A B and Clark J S 2016 Multiyear drought-induced morbidity preceding tree death in southeastern US forests Ecol. Appl 26 17-23

[33] Schabenberger and Gotway 2005 Statistical methods for spatial data Analysis Chapman \& Hall (Taylor \& Francis)

[34] Filipchuk A, Moiseev B, Malysheva N and Strakhov V 2018 Russian forests: A new approach to the assessment of carbon stocks and sequestration capacity Environmental Development $\mathbf{2 6}$ $68-75$

[35] Zhu Q, Liu Y, Jia R, Hua S, Shao T and Wang B 2018 A numerical simulation study on the impact of smoke aerosols from Russian forest fires on the air pollution over Asia Atmospheric Environment 182 263-274

[36] Marengo J A, Alves L M, Alvala R C S, Cunha A P, Brito S and Moraes O L L 2018 Climatic characteristics of the 2010-2016 drought in the semiarid Northeast Brazil region Anais da Academia Brasileira de Ciências 90(2) 1973-1985

[37] Boori M S, Paringer R, Choudhary K and Kupriyanov A 2018 Supervised and unsupervised classification for obtaining land use/cover classes from hyperspectral and multi-spectral imagery Proc. SPIE 10773, $6^{\text {th }}$ International Conference on Remote Sensing and Geoinformatics of the environment (RSCy 2018) 107730L 1-11

[38] Palmer W C 1965 Meteorological Drought US Department of Commerce, Weather Bureau, Washington, DC, USA 30

[39] McKee T B, Doesken N J and Kleist J 1993 The relationship of drought frequency and duration to time scales Proceedings of the 8th Conference on Applied Climatology 17(22) 179-183

[40] Karl T and Knight RW 1985 Atlas of monthly Palmer hydrological drought indices (1931-1983) for the contiguous United States Natl. Clim. Data Cent

[41] Khadr M 2017 Temporal and spatial analysis of meteorological drought characteristics in the upper Blue Nile River region Hydrol. Res 48(1) 265-276

[42] Beaudoing H and Rodell M 2016 NASA/GSFC/HSL, GLDAS Noah Land Surface Model L4 monthly 0.25 x 0.25 degree V2.1, Greenbelt, Maryland, USA, Goddard Earth Sciences Data and Information Services Center (GES DISC) URL: https://disc.gsfc.nasa.gov/ datasets/GLDAS_NOAH025_M_V2.1/summary?keywords=GLDAS

[43] Pettitt A N 1979 A non-parametric approach to the change-point problem Appl. Stat 126-135

[44] Buishard T 1984 Tests for detecting a shift in the mean of hydrological time series J. Hydrol $\mathbf{5 8}$ 51-69

[45] Boori M S, Paringer R, Choudhary K, Kupriyanov A and Banda R 2018 Land cover classification and build spectral library from hyperspectral and multi-spectral satellite data: A data comparison study in Samara, Russia CEUR Workshop Proceedings 2210 390-401

[46] Boori M S, Choudhary K, Evers M and Kupriyanov A 2017 Environmental dynamics for Central Dry Zone area of Myanmar International Journal of Geoinformatics 13(3) 1-12

[47] Giri C, Pengra B, Zhu Z, Singh A and Tieszen L L 2007 Monitoring mangrove forest dynamics of the Sundarbans in Bangladesh and India using multi-temporal satellite data from 1973 to 2000 Estuar. Coast. Shelf Sci 73(1) 91-100

[48] Pavelyeva E A 2018 Image processing and analysis based on the use of phase information Computer Optics 42(6) 1022-1034 DOI: 10.18287/2412-6179-2018-42-6-1022-1034

[49] Boori M S, Paringer R, Choudhary K and Kupriyanov A 2018 Comparison of hyperspectral and multi-spectral imagery to build a spectral library and land cover classification performances Computer Optics 42(6) 1035-1045 DOI: 10.18287/2412-6179-2018-42-6-1035-1045 
[50] Bibikov S A, Kazanskiy N L and Fursov V A 2018 Vegetation type recognition in hyperspectral images using a conjugacy indicator Computer Optics 42(5) 846-854 DOI: 10.18287/2412-61792018-42-5-846-854

[51] Belov A M and Denisova A Y 2018 Spectral and spatial super-resolution method for earth remote sensing image fusion Computer Optics 42(5) 855-863 DOI: 10.18287/2412-6179-2018$42-5-855-863$

\section{Acknowledgment}

This work was partially supported by the Ministry of education and science of the Russian Federation in the framework of the implementation of the Program of increasing the competitiveness of Samara University among the world's leading scientific and educational centers for 2013-2020 years; by the Russian Foundation for Basic Research grants (\# 15-29-03823, \# 16-41-630761, \# 17-01-00972, \# 1837-00418), in the framework of the state task \#0026-2018-0102 "Optoinformation technologies for obtaining and processing hyperspectral data". 